\title{
The Resettlement of Central American Men in Canada: From Emotional Distress to Successful Integration
}

\author{
Kevin Pottie, Judith Belle Brown, and Samuel Dunn
}

\begin{abstract}
Stress associated with immigration, particularly forced migration, may aggravate men's emotional distress and reluctance to seek help. This qualitative study of Central American immigrant and refugee men explored the process of coping with distress during resettlement. "Losing the way," a common theme of resettlement, was frequently a solitary struggle accompanied by anxiety, depression, and/or abusive behaviours. "Finding the way," grieving socio-cultural losses and seeking help, became possible when participants were able to accept responsibility for their behaviour. The role of "belonging" (support groups, jobs, family obligations) was a key motivating factor in the process of accepting responsibility and personal change.
\end{abstract}

\section{Résumé}

Le stress associé à l'immigration, en particulier à l'immigration forcée, peut aggraver la détresse émotionnelle des hommes et accentuer leur répugnance à rechercher de l'aide. Cette étude qualitative d'hommes immigrants et réfugiés provenant des pays de l'Amérique centrale explore comment les intéressés arrivent à se débrouiller et à faire face à leur situation. "Perdre la voie ", un thème commun en matière de réinstallation, s'avère être souvent une lutte solitaire accompagnée d'angoisse et de dépression, avec ou non des comportements violents.

"Trouver la voie ", c.à-d. pleurer les pertes socioculturelles et rechercher de l'aide devint possible seulement lorsque les participants furent capables de prendre la responsabilité de leurs propres comportements. Le sens d'appartenance (groupes de soutien, emplois, responsabi- lités familiales) joua un rôle capital dans le processus de responsabilisation personnelle.

\section{Introduction}

he socio-cultural changes that accompany resettlement, particularly in cases of forced migration, are emotionally distressing. ${ }^{1}$ Migrating men in particular face gender-specific losses and stressors ${ }^{2}$ that may make integration and help-seeking more difficult. ${ }^{3}$ This research paper focuses on men coping with emotional distress in the milieu of socio-cultural adaptation and provides a narrative perspective on Central American men integrating into a new country.

The Central American countries of El Salvador, Guatemala, and Nicaragua share a history of political violence and social unrest. More than 90 per cent of Central Americans living in Toronto originally fled their homeland due to political oppression and conflict. ${ }^{4}$ Such unrest has left migrants from these countries at high risk for emotional distress ${ }^{5}$ and in need of more innovative provision of health care. ${ }^{6}$ Latin American immigrant men ${ }^{7}$ frequently share a common history of trauma, torture, and violent oppression from their homeland and as a result suffer significant loss of socio-political status and struggle against language and employment barriers.

\section{Literature Review}

Psychological Distress in Immigrants and Refugees Exposure to violence and political persecution in the country of origin, as well as language barriers, unemployment, and socio-economically deprived urban environments in the resettlement city, leave Central American immigrants particularly vulnerable to profound emotional distress. Adjusting to a new economic, social, and cultural climate is an 
emotionally painful process for most immigrants. Although the experience of immigration itself does not produce mental illness ${ }^{8}$ the multiple processes of dislocation, movement, and resettlement may together place immigrants at risk for emotional problems. ${ }^{9}$

War, poverty, unequal land distribution, and political persecution in Central American countries have led to the killing, torture, disappearance, and displacement of thousands in the post-war era. ${ }^{10}$ Refugees, many of whom have experienced war, state-endorsed terror, and political persecution, are at particularly high risk for mental health problems, such as anxiety, stress, depression, and other emotional difficulties. ${ }^{11}$

Salvendy ${ }^{12}$ identifies language and cultural barriers, a large socio-economic gap between the society of origin and the host country, and previous psychosocial maladjustment as contributing to the stress of migration and resettlement. The inability for the host country to offer language and culturally appropriate health services may hinder helpseeking behaviour. ${ }^{13}$

\section{Masculine Health Beliefs and Behaviours}

Masculine health beliefs often promote secrecy and isolation $^{14}$ rather than help-seeking and community involvement. Men often have difficulty articulating their distress and may "act out" their emotions in an attempt to regain control or right expectations. ${ }^{15}$ Psychological distress may therefore manifest in the form of alcohol and drug abuse, risk-taking, and physical violence. ${ }^{16}$ Umberson et al. ${ }^{17}$ suggest that violent behaviour may be an alternative expression of emotional distress that results from socio-cultural stresses. Courtney ${ }^{18}$ argues that these masculine health-related beliefs and behaviours contribute to gender mortality (homicide, suicide) and morbidity differences; for example, the higher incidence of suicide among males.

Gender socialization influences health beliefs and behaviours. ${ }^{19}$ Brannon ${ }^{20}$ identified four major components of the Western male role: the need to be different from women; the need to be superior to others; the need to be independent and self-reliant; and the need to be more powerful than others, through violence if necessary. Sabo and Gordon ${ }^{21}$ point out, however, that the root of men's higher risk for disease is not simply based in men's individual psyches but is reflected in men's roles, routines, and relations with others and that these roles are fixed in the larger historical and socio-cultural relations that constitute gender order. Political, economical, and ideological structural changes are therefore necessary if personal changes are to have any lasting benefit. ${ }^{22}$

Freire $^{23}$ suggests Latin American immigrant men and women differ in their "core identities"; for example, having paid work is an important "core identity" among Latino men whereas women focus more on the family. Since many of these immigrant men have difficulties finding employment in their field of expertise, due to unavailability of jobs or unrecognized credentials, they are unable to provide financially for their families, resulting in loss of socio-economic status and feelings of inadequacy.

Latino men and women also differ in their behaviour in relation to emotional problems and help-seeking behaviours. While women may present with headaches or crying as symptoms of distress, men may express distress in acting out behaviours such as marital violence or alcohol abuse. ${ }^{24}$ Freire states that men typically "resist seeking professional services, [they] do not attempt to create or use existing support systems, and even reliance on friends tends to be minimal or nonexistent." 25 She further suggests that Latin American men have difficulty verbalizing their emotions, particularly vulnerable ones, such as fear, anxiety, and anger. Feelings of inadequacy that result from a decline in occupational status contributed to this difficulty in communication. While the women in Freire's study ${ }^{26}$ were able to seek help or assistance for financial or health problems in Canada, men were unable to respond to these challenges in a constructive way.

Freire describes a "gender differentiated pattern of response" 27 between newcomer Latino men and women. In migrating to Western countries, Latino men must adapt to a new gender order: a culture-norm that confers more power and rights to women in relation to the traditional patriarchal societies of Central America. ${ }^{28}$ These immigrant men confront new societal values and behaviour patterns and, unfortunately, they may lack the skills to obtain valued goals within this new society. ${ }^{29}$

\section{Emotional Distress "Nervios”}

Latin American immigrants in both the United States and Canada experience a wide range of emotional difficulties, including confusion, anxiety, tension, and depression. ${ }^{30}$ Guarnaccia et al. ${ }^{31}$ in their review of the literature on Puerto Rican mental health in New York, emphasize the importance of focusing on culturally meaningful expressions of distress such as the cluster of emotional difficulties identified in the Latin American population as "nerves" or nervios.

According to medical anthropologist Janis Jenkins, nervios is "an indigenous cultural category widely used in Latin America for a variety of forms of distress and disease.... and may refer to a variety of bodily and affective complaints." 32 While social theorists have argued that nervios is a metaphor for political oppression and poor socio-economic status ${ }^{33}$ or a "somatization" or "embodiment" of terror, ${ }^{34}$ it is nevertheless a sign of distress that impacts not only individual well-being but also the family 
and social relations of the sufferer. Nervios may be expressed somatically as headaches, dizziness, and difficulty sleeping, ${ }^{35}$ or as emotional problems such as loneliness, isolation, nostalgia, and boredom. ${ }^{36}$ Individuals may consider the condition "normal" to the extent that "having nerves" or "being nervous" is a part of everyday life ${ }^{37}$ and they tend not to seek help until "having nerves" is perceived as restrictive or chronic in nature.

Studies of Latin American immigrants report that men tend to avoid discussing or dealing with health problems, ${ }^{38}$ but these studies fail to analyze the gender and cultural dynamics of care seeking. Farias, ${ }^{39}$ studying nervios in both Salvadoran refugee men and women in the United States, found that women typically expressed nervios with symptoms of headaches and other pains, crying uncontrollably, and loss of breath. Women identified an inability to support family and a loss of community relations as associated stressors. Men predominately described nervios with symptoms of weakness, fear of losing control over violent impulses, alcohol abuse, and nightmares. Men identified loss of functional capacity, inability to provide economically, marital conflicts, and social isolation as associated stressors. Nervios, from a male perspective, was seen as an infringement on being "able-bodied" and was expressed in a variety of ways, most commonly as loneliness, isolation, and anxiety.

\section{Methods}

Study Design

This qualitative study focused on data from in-depth interviews with nineteen Central American men living in Toronto, with supplementary data from field observations and a men's focus group. Key informants' discussions helped assure culturally sensitive research. ${ }^{40}$

Ethics approval was obtained from the Review Board for Health Science Research Involving Human Subjects at the University of Western Ontario and the Human Participants Review Committee at the Office of Research Administration at York University.

\section{Recruitment and Sampling}

The nineteen interviewed men originated from El Salvador, Guatemala, and Honduras. These in-depth interview participants were recruited through a Hispanic social worker, key informants, and contacts of one of the authors (Pottie). This "snowball" sampling technique ${ }^{41}$ facilitated interviewer-participant trust and allowed recruitment of participants wary and not yet connected to formal medical services.

The participants originated from El Salvador (thirteen), Guatemala (three), and Nicaragua (three). Fifty-five per cent of participants formally identified themselves as refu- gees, with just over half arrived in Canada prior to 1990. Fifty-eight per cent were married and 34 per cent reported being separated or divorced. The participants ranged in age from 21 to 67 years of age with the vast majority (89 per cent) being between 21 and 50 years of age. The participants showed a diverse range of educational backgrounds ranging from some elementary education to having completed university degrees, the majority (64 per cent) reporting some high school education.

All participants, refugee claimants, refugees and immigrants in Canada, were entitled to health coverage, social assistance, English- or French-as-a-second-language training, and employment and student permits. Due to the participants' high level of forced migration, this study did not specifically seek to differentiate refugees and immigrants.

\section{Data Collection}

Semi-structured in-depth interviews were used to collect data relating to participants' personal backgrounds and resettlement experiences, emotional health problems, and experiences with health care services (see Figure 1). All interviews lasted one to one and one-half hours and were conducted at a location selected by the participant.

In an effort to better understand the socio-cultural context of the participants, two of the authors (Dunn and Pottie) attended several community events (soccer matches, church services, health centre events) and recorded field notes based on informal discussions and observations. Four Spanish-speaking Latin American immigrants served as key informants (female social worker, female medical doctor, male addiction councillor, and female language teacher). These informants provided valuable culture and gender-relevant perspectives and knowledge about utilization of health care services and provided feedback on research findings. A repeat individual interview and a late-stage focus group (seven male participants) were conducted to seek feedback on the researchers' preliminary synthesis of the data.

All participants and key informants were offered an honorarium of $\$ 20$ (Canadian) for in-depth interviews and focus groups. All interviews were audiotaped and transcribed verbatim in the language chosen for the interview (ten in Spanish, nine in English) or focus group (Spanish).

\section{Data Analysis}

The constant comparative method of grounded theory ${ }^{42}$ was used in the analysis of the in-depth interviews. The iterative analysis with ongoing analytic reflections enabled the researchers to move deeper into practical and theoretical issues of masculinity and its impact on emotional distress during resettlement. 
Figure 1

Sample In-depth Interview Questions

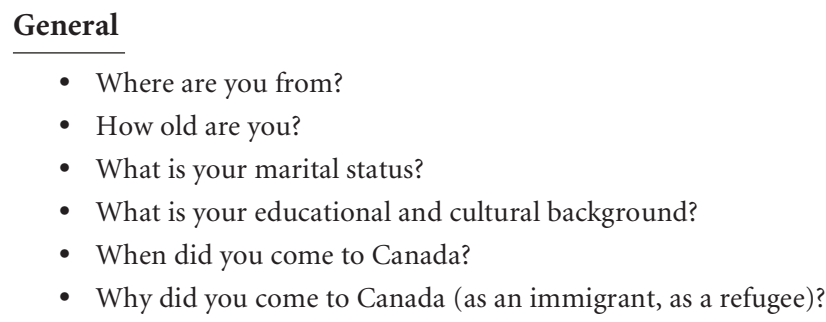

Health and illness and emotional distress

- What have been your experiences, positive or negative with your health in Canada?

- Have you had any problems with your nerves, emotional distress or depression since you have lived in Canada?

- Do you have any stories to tell about when you had difficulties with your nerves?

- In your opinion, what are the differences between nerves and mental health problems?

\section{Utilization of mental health services}

- How do you deal with problems with nerves, stress or depression?

- Do you deal with them privately or with other people?

- Where do you go to get help with nerve problems: nervios (priest, friend, natural healer, wife/girlfriend, family member, psychologist, family doctor)?

- What health services have you used in Canada?

- Do you have any memorable stories about when you tried to use health services?

- What difficulties do you think Central American men face with health services in Canada?

\section{General health: perspectives, opinions and ideas}

- In your opinion what is the biggest health problem Central American men face in Canada?

- How do you think this problem should be dealt with?

- What should be done to make health services more accessible for Central American men?

- Do you anything else to add with regard to nervios and emotional distress in the settlement of Central American men?

All generated data, in-depth interviews, analytic reflections, late-stage focus group of men, and field observations were then analyzed together. The variety of data sources allowed the researchers to compare and contrast several perspectives on men's health-related beliefs and behaviours. Ultimately an understanding of the participant's stories of adaptation and emotional distress transpired.

\section{Trustworthiness}

In-depth interviews were felt to reach saturation at nineteen and re-interviewing of three participants was conducted as an additional check for credibility and saturation (evidence of no new data). Member checking occurred through re-interviewing and a focus group of male participants.

\section{Findings}

The participants described a range of struggles and life changes ranging from personal and occupational failures, addictions, and depression, to personal growth, opportunities, and community involvement. The findings are reported under the themes of "Surviving the past," "Keeping it in," "Losing the way," and "Finding the way." Figure 2 represents a diagrammatic overview of the process of adaptation.

(Quotations presented in parenthesis have been translated from Spanish.)

\section{"Surviving the Past"}

Surviving war

Most of the participants had survived experiences of war and conflict and all had been affected emotionally, physically, or 
Figure 2: Resettlement of Central American Man

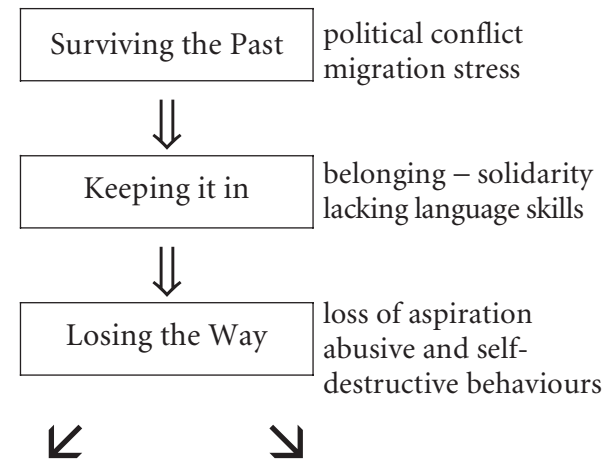

Reconnecting

Disconnecting

$\downarrow$

Finding the Way

Accepting responsibility,

peer support-shifting

identities

economically by violence in their home country. Many also identified family members who were either killed or "disappeared" as a result of the counter-insurgency campaigns of government-backed armies in the region. These sociopolitical experiences with war and oppression were identified as the beginning of the adjustment process or, conversely, disconnection. Roy, coming from El Salvador stated:

We are coming from conflicted countries, where there was war. We are coming from war, from seeing chopping, killing, torture, and some of us have been tortured. So we are coming with very high emotional and psychological problems.

Reflecting on his experiences in Guatemala in the 1970s, during the country's thirty-six year civil war, Nery stated:

I lost a brother. They accused him that he was a collaborator in the Movement and I lost him. He was twenty-four. A lot of people died in nineteen-seventy. If you talked, the guerrillas killed you. If you didn't talk, the army killed you, so we were between the wall and the arrow, you know what I mean?

\section{Surviving migration and resettlement}

This section, concerning resettlement stressors, introduces several key and often overlapping barriers: language difficul- ties, loss of confidence, unemployment, and lack of familiarity with services. These barriers bring into focus the initial struggles the participants faced in starting new lives in Canada and in accessing formal or informal care when emotionally distressed.

Francisco arrived in Canada from Guatemala in 1989. A university graduate, he arrived with several positive expectations concerning life in a new society. But like several other participants in this study, he soon suffered from feelings of disappointment and inadequacy:

I had just come to Canada. The next day I thought, I want to start working. It didn't happen. The real thing was that I had to learn English. I didn't know anything about the English language so I went to some classes. I was sitting in the chair after being in university, sitting in these classes, and not knowing anything about English. It was so sad.

Marcelo also carried a sense of hope with his migration to Canada:

I thought it would be easy to start a new life. I was very optimistic. To find a job, hold a job, to have a girlfriend, help someone else out. I could not see at that time that the biggest barrier would be language. That is the worst thing.

Language was identified as a key barrier to finding employment. Several participants also reported difficulties communicating with health professionals in both community and hospital settings. Some participants argued that men lacked the motivation to look for services while others maintained that underutilization was a structural problem related to language barriers. Alejandro, for example, stated:

My wife was in the hospital in 1991. There was no doctor, no psychiatrist, no nurse, nobody who could speak Spanish. I felt so bad, you know.... I was losing hope. Like ah, close to suicide, really thinking so much. But no, I never found anybody who could...who can speak [Spanish].

\section{"Keeping It In"}

Questions about problems with nervios or depression repeatedly elicited stories on how it is "hard to be a man" or how "people don't understand how much responsibility a man has." Conversations about alcoholism or domestic abuse were deeply entangled with the meaning of manhood. Competing narratives emerged how being a man shaped individual health or response to illness. A key finding of this study was that the underutilization of informal and formal sources of emotional support among Central Americans is linked to constructions of what it means to be a man: ser hombre. 


\section{Machismo as a source of belonging}

Machismo was associated with a reluctance of men to seek help for health problems. Not talking about emotional difficulties, "keeping it in," was viewed as a characteristic of being a man. Being assertive, proving oneself to others, not showing weakness, and not bothering friends or family about personal problems were frequently occurring themes in the interviews and focus groups. Male participants did not seek help for emotional distress for a number of reasons: men hide or conceal health problems because of pride, they lack trust in the people around them; they consider it "unmanly" to discuss their emotions, they don't want to worry others about their health status; or they blame others for their bad health.

One participant, Miguel, attributed his reluctance to deal with health problems to an aspect of machismo:

The Latino man, we have a problem. It is machismo: not letting ourselves to be less than women. Believing ourselves to be superior than women. The Latino man, we like to put up fronts. Be strong, we are the ones that take charge in the house. We are the chiefs of the house. That is the problem. That is why I think that it is easier to notice certain physical or mental weaknesses in women. Men try to hide it, not to show it but to hide it. That is machismo.

Several participants insisted that being a responsible man was "part of their culture" and that men and women had certain roles to fulfill in their daily lives. Miguel said:

The man is the one that brings home the bread and organizes the house and the internal organization of the home revolves around the woman. So we are born with this responsibility. We were brought up with that mentality. So it is difficult to come here (Toronto) and...change overnight.

Many participants felt that "they were less machista" since migrating to Canada because they "were not in their culture anymore" and because women had more protection and rights in Canada than in their home country.

I used a lot of machismo over there (home country). But I arrived here and my machismo went down. Why? Because of the law. Because of the laws that exist in this country. And now it is hard for me to change my machismo. But I am trying....

\section{"Losing the Way"} Spiralling downward

Problems with nerves, alcohol, depression, loneliness, violent behaviours, and other forms of distress were often described by participants in terms of losing direction in life, losing a sense of personhood, or "being lost" or "disappearing." "Losing the way" and the resultant downward spiral were often associated with lack of language skills, cultural marginalization, financial resources, friends or sexual relationships, as well as being unable to fulfill goals and aspirations.

Miguel, a 42-year-old university graduate from Guatemala, said:

In Guatemala I was always in charge, but in Canada I have to share little things. And that makes me feel like I am losing my identity; I was losing my identity as the one who brings home the money, because here [Canada] if I can't have a job, I [must] apply for Social Services. I said: “Miguel is gone, he doesn't exist anymore." So this kind of feeling made me feel lost in this country. It is very hard.

Roy, who arrived in Canada in 1994 as a refugee, said:

When we come to Canada...we find big barriers here; for example, language, culture, money, everything is new for us. They are taking us from what you call the Third World into a First World country. The culture is very totally different the way that they both behave and act. And so it is a very great impact. And they just treat us just like animals.

Migration for political or economic reasons caused disruptions in their lives. Given that most of the men in this study migrated to Canada at between twenty and forty years of age, many had aspirations of achieving a particular occupation or establishing a family. Thus, the ways in which disruption is influenced by a past dominated by political conflict and a present influenced by conflict from traditional constructions of masculinity provide an important context for the analysis of the emotional problems faced by the participants.

\section{Behaviours expressing psychological distress}

Behaviours, rather than verbal expressions of emotions, were frequently reported by participants in relation to distress during adjustment. Many participants described struggles with alcoholism, drug addiction, weight gain, abusive behaviors, sexual promiscuity, and suicidal ideation. Like nervios, these behaviours were expressions of the social, cultural, and economic struggles in their lives. "Forgetting" through drinking was a common strategy employed by men to deal with unemployment, family conflicts, boredom, and loneliness. As 44-year-old Edgar described:

...by the second year after coming to Canada I feel so depressed, because I didn't...didn't—couldn't find a job. I start drinking. 
Mario from El Salvador said:

When I arrived in Canada this problem, or this illness was intensified. It was worse than in my country. I imagine, I am sure that it was a kind of frustration in finding myself in a new culture, a new world, and above all, with a very large barrier which was language. Upon arrival in Canada, well, I already smoked marijuana every day and several times a day for many years. I drank alcohol from the age of thirteen until I arrived here, almost every day too. But then here in Canada I started getting into cocaine. Then my illness in addiction to drugs was bigger here in Canada than in my country.

Several male participants reported substance abusive together with violent abusive behaviours toward women. Alcohol abuse and domestic violence often had existed prior to migration, but these problems either worsened or were simply not tolerated by women once in Canada. After describing his divorce from his wife and his efforts to curb his violent behaviour towards her, Francisco stated:

My physical health was okay, but my mental health was not good; because when I went through the separation with my wife, I was kind of under restraint with Immigration.... In Guatemala you wouldn't have this kind of situation. But here I was under restraint and I tried to kill myself. I was in the bath when I tried get out by the window and run and run, and because I couldn't deal with my family problems like I did in Guatemala. So I said everybody is against me, everybody wants me to be nothing, everyone wants me to be quiet and don't say anything.

\section{"Finding the Way"}

In contradiction to stereotypes about the macho Latino man that emphasize sexual prowess and stubborn individuality, participants' success stories demonstrated that connecting with support groups, friends, and organizations allowed one to accept responsibility for one's behaviour. This ability to accept personal responsibility for one's behaviour was a key factor that influenced participants' ability to reconstruct their masculine identities and "move on," the term most often used by participants in reference to successful integration. Less than half of the participants described success stories in their narrative account of resettlement.

\section{Accepting responsibility}

An overwhelming number of participants asserted that "moving on" and maintaining well-being was a matter of personal responsibility. Walking, resting, reading, playing soccer, learning English, keeping busy, staying organized, eating healthy foods, and abstaining from drinking and smoking were identified as key sources of emotional wellbeing. Keeping composed and having control over your own body were also considered ways to maintain individual health as well as good relations with friends and family. Since most of the participants had been married or had children, meanings of manhood were often intertwined with being a husband and/or father. Ricardo said:

I was always a man to work for his family and children. I have enjoyed being responsible for many things..., in everything. When one is responsible it is a very good thing. Because a man's responsibility has to be very effective, positive... to sow the seed for the being that is coming, for the son that is about to come, for children to grow up with a good experience, with a father that has given them good guidance that will serve them in the future.

For several participants, another important facet of "moving on" was relearning what it means to be a man. Francisco found a way to deal with his violent behaviour towards his wife by rethinking his own sense of responsibility to himself and to the people around him:

What I wanted to do is to keep my family together and I realized that I was the one who has a problem; I was blaming my wife and my kids. I thought they didn't understand me, but I got information from the community centre. I then realized that I was the one who had problem with my dealing with my anger. And I identified that I was losing my identity as a man because I couldn't deal with the situation like I did in Guatemala.

The first thing is to learn that we are responsible for our own behaviour; this is a main focus. You are responsible for any behaviour. Women are not responsible; she doesn't deserve to be beaten. It is not her fault if we are violent. It is not her fault if we feel sad, upset, angry, it's not her fault; it's our responsibility to express our feelings.

I am still learning how to be a man; a different one than I was in (home country). Now, I learn how to cry. When I was a little kid my Dad used to say boys don't cry, girls cry, so I learnt how to express my feelings. I was suppressed, if we expressed our feelings we had to use violence. This is the way my Dad used to do it. So now I learn not to do it in the way I learned when I was a kid. I think that I'm not the same person.

\section{Connecting to support groups}

Connecting to social and support groups provided participants with emotional support and facilitated new constructions of masculinity. Some of the men eventually sought out emotional support through organizations such as Alcoholics Anonymous (AA) and community-based support groups. 
Although the degree of social connectedness varied from participant to participant, as did the ability of different participants to meet friends and maintain friendships, having social ties was considered important in everyday life. Francisco found a way to deal with his violent behaviour by joining a parenting group.

I had stopped going to school for a week and then I saw a sign in the hall of the school. It was about a parenting group. This group had about twelve women and I joined them. The first session I was crying. I just opened the door and I said: "This is a parenting group?" They said yes, so I started crying and they listened to me, they were saying "If you want to talk, just talk. You want to cry, just cry, but we will not judge you, we will not criticize you," and then they were listening to me. I told them that I have problems at home and I don't know how to deal with them, and it was when I realized I was under depression.

Roy described the ways in which the Spanish-speaking AA program had helped him:

...Because in the way it is very flexible. For example, those steps are saying things like this: life is this, you can take this way, you can take this [way]. They are putting it as a mathematic. They are giving you a program and then...this is the way I'm teaching you, but then if you find another way that can go to the same result, that's fine.

Imanuel struggled for several years to learn English and find a job:

Canada was really bad in the beginning. Why it was really bad is because all the time I was inside the house with my nerves, because the problem I had was that I didn't speak English, and I didn't know nothing. But after a while I go by bicycle two blocks and I find a park and there's a lot of Spanish people there, so I have friends, and then I see Canada differently.

Participants also identified male friends and social connections as important sources of well-being. Friends were a source of emotional support, as well as a source of motivation to quit drinking or smoking. Having friends is a way to counter feelings of loneliness in a new society.

In the case of Ricardo, meeting fellow Spanish-speaking men was an important step towards improving his life after problems with depression, sadness, and loneliness:

I have over seven years of being here and life has changed a lot in me. I am not the same as the one who came here back in those times, not knowing anything. I know all of Toronto; I know the area where I live. Now I have friends, I have people with whom I share marvelous moments.
My job helped me a lot and school also gave me a lot of support. But one also needs friendships, to have friends, to participate in something, something good that can be beneficial to the community.

\section{Discussion}

The rich narratives described in this study unmask the painful adjustment struggles faced by many Central American immigrant men in Canada. The findings provide insight into how disenfranchised men can accept personal responsibility and change within a supportive environment of other immigrant men, and the risk of abusive behaviours in the context of unmitigated psychological distress. The narratives reflect shifts in participants' identities and how these masculine identities are contingent on historical and changing socio-cultural contexts. ${ }^{43}$

This study also identified the theme of "losing the way," the spiralling downward process that preceded an effective identity reconstruction for some participants or lead to a further disconnection for others. The findings also reconfirm observations from other immigrant studies that identify language as a key barrier to community resources ${ }^{44}$ and suggest employment ${ }^{45}$ and support systems ${ }^{46}$ are key facilitators to men's adjustment.

\section{"Keeping It In:" Gender and Culture Beliefs}

The participants in this study were reluctant to acknowledge or seek help for psychological distress. This may have been because participants had a fear of showing weakness or were ill-equipped to articulate their emotions, particularly negative ones such as fear, anger, and anxiety. ${ }^{47}$ The origins of "keeping it in" and machismo may very well date back in Latin American history to protective and productive roles ${ }^{48}$ and a sense of belonging among men.

It was frequently participants' prolonged unemployment and loss of social status that led to a loss of hope and aspirations; a loss of control that led to behaviours that were often violent or self-harming. Integrating into community life in Canada demanded a shift in certain masculine beliefs and behaviours, particularly a shift away from abusive behaviours toward women. Participants' responsible or irresponsible behaviours had implications for individual health and family well-being.

The findings in this study suggest a conflict between traditional machismo (patriarchal values) and transitional egalitarian forces within the Canadian immigrant context, terms defined by Rogler ${ }^{49}$ that relate to marital power identity. Participants identified women as support persons, but rarely as significant agents of change. But it was often through women that the participants were confronted with the more egalitarian values of Canadian society. Partici- 
pants saw themselves as the head of the family, financially and often emotionally, responsible for taking care of the needs of the family. It may have been the men's loss of power status ${ }^{50}$ or the conflict of traditional family roles that limited the effectiveness of women alone in facilitating the men's identity adjustment.

\section{"Losing the Way"}

During the resettlement process participants frequently struggled with their changing identities, feeling lost and in emotional distress. This distress was initially expressed through unhealthy behaviours rather than through helpseeking behaviours. Perceived or real losses in social status appeared to provoke alcohol use, abusive and violent behaviours, and promiscuous sexuality. Participants often appeared to get lost during their adjustment process, and in seeking to right the way, they often acted violently toward themselves or others. The behaviours accompanying emotional distress may have been used as a means of regaining feelings of control ${ }^{51}$ and the severity of the situation was often suggested by chronicity, intensity, and rigidity of the problems. This study suggests that abusive behaviours can play a significant role in identifying men suffering from unmitigated psychological distress.

This sense of losing the way preceded any acknowledgement of emotional problems and subsequent acknowledgement of personal responsibility. Participants who were unable to accept some responsibility were unable to reconstruct their identity and continued to descend to devastating consequences, such as disabling substance abuse or isolating depression.

These findings are consistent with the downward social movement and psychosocial distress that Bourgois ${ }^{52}$ describes in his ethnography, In Search of Respect, in which he captures the struggles and suffering of Hispanic Americans in East Harlem, New York. This spiral descent also parallels the downward spiral described in narratives of chronic illness ${ }^{53}$ and addiction. ${ }^{54}$ Charmaz $^{55}$ describes this cycle of loss and social descent: "Serious chronic illness...results in the spiralling consequences such as the loss of productive function, financial crises, family strain, stigma, and a restricted existence... affected individuals commonly not only lose self-esteem, but even self identity." Although not all the participants had mental illness, all participants had suffered losses relating to functional capacity, family responsibility, cultural, and community ties.

\section{"Finding the Way"}

Despite participants' acknowledgement of the role of personal responsibility and self-reliance, "finding the way" was never solely an individual act; rather, it depended on connect- ing socially with other adjusting immigrants in the community. The participants who had managed to "find the way" had often connected to a men's support group that facilitated the acceptance of new roles and responsibilities.

The historical and cultural context of Central American men provides insight into the relevance of masculine identities and the slow and often traumatic process of shifting these identities. Rechtman ${ }^{56}$ suggests that members of a society at war often share common values, struggles, and illnesses even though their exposures to trauma may vary. It is this belonging and solidarity, a belonging that Taylor ${ }^{57}$ describes as a universal need, which may at once provide strength and resiliency in times of trauma in the homeland but later inhibit adaptation to a new society. The need to maintain a sense of connectedness with other Latino men suggests that reconstructing identities must take place without losing a sense of connectedness to a culture and gender group.

Peer support groups for men played a large role in helping participants shift and reconstruct their responsibilities and male identities. Belonging was a key facilitator in accepting responsibility. And being connected to a community and social support network was significant moderator of emotional distress. A study by Jarama et al..$^{58}$ on disabled Central Americans immigrants found that decreased social support was associated with increased anxiety and risk for depression. Another study with Latin American immigrants ${ }^{59}$ also supports the importance of "belonging" with its finding of a significant negative association between church attendance and suicide.

\section{Implications for Practice and Research}

The findings in this study have severalimplications for clinical practice and health and social service delivery. While nervios may be a metaphor for the everyday struggles with emotional distress experienced by immigrants, it may also signal the onset of more serious mental illness. This study highlights the need for awareness of cultural idioms of distress among primary care professionals and program and policy planners.

The prevalent male belief in "keeping it in" suggests a need for gender-specific health and social services for Spanish-speaking immigrant men, especially those who have experienced political conflict and violence in their home countries, are unemployed, or lack English-language skills. These health and social services should reflect male gender roles through links to employment and language services and promotion of the role of fatherhood. Focusing on action rather than verbal expressions of feelings may represent a gender-targeting approach to mental health services.

Health care professionals, emergency and primary care physicians in particular, need to be aware that violent and abusive behaviours may be a sign of psychological distress. It 
is important that these professionals appreciate the role of peer support groups in mitigating emotional distress and in enabling socio-cultural adaptation. A male support group may broaden a man's cultural perspective without threatening his sense of belonging to the male gender. Both formal and informal support groups should be developed and further research undertaken to explore the use of support groups in assisting immigrant men in adjusting to societal norms.

\section{Conclusions}

The participants in this study revealed a range of struggles and life changes ranging from personal failures, addictions, and depression to personal growth, opportunities and community involvement. Stories of "survival," often riddled with violence, loss, and resettlement stress, provided a context for stories in which participants invariably "lost the way." Language, lack of male-friendly services, and general lack of awareness of community services predominated as barriers to formal and informal health services. However, it was the culturally endorsed belief in "keeping it in" that was often the main obstacle to reconstructing healthy male identities. "Losing the way" frequently left the participants emotionally distressed and prone to transgressive behaviours. The inability to reconnect with society had devastating consequences such as disabling substance abuse, depression, and suicide attempts. "Finding the way," when it did occur, involved accepting personal responsibility for one's behaviour. The sense of belonging that came from associations with support groups, new friendships, and community connections was a key factor in facilitating acceptance of personal responsibility.

In summary, this study provides new insights into men's process of accepting responsibility and recovering from the losses that accompany migration and resettlement. The participants' descriptions of their struggle to adapt can guide health care professionals, service agencies, and program and policy makers in providing gender sensitive and culturally appropriate assistance to this vulnerable population.

\section{Notes}

1. Morton Beiser, Strangers at the Gate: The 'Boat People's' First Ten Years in Canada (Toronto: University of Toronto Press, 1999).

2. M. Freire, "The Latin American Exile Experience from a Gender Perspective: A Psychodynamic Assessment," Refuge 14 (1995): 20-25.

3. D.J. Rickwood and V.A. Braithwaite, "Social-Psychological Factors Affecting Help-Seeking for Emotional Problems," Social Science \& Medicine 39, no. 4 (1995): 563-672.

4. Statistics Canada, Ministry of Citizenship, Culture and Recreation, Research and Data Group (Ottawa, Canada, 1991).

5. C. Losaria-Barwick, "Mental Health of Refugees: Opportunities and Challenges, A Summary of Issues Affecting Mental Health of Refugees" (developed for the Ministry of Citizen- ship, Community Consultation on Refugees, 1992); J. Jenkins, "The State Construction of Affect: Political Ethos and Mental Health among Salvadoran Refugees," Culture, Medicine and Psychiatry 15 (1991): 139-65; D. Meredith, "Guatemalan Refugees and Their Process of Adjustment in Toronto," (master's thesis, York University, Toronto) 1992.

6. R. Desjarlais et al., World Mental Health: Problems and Priorities in Low-Income Countries (New York: Oxford University Press, 1995); V.N. Salgado de Zinder, R. Cervantes, and A. Padilla, "Gender Differences in Psychological Stress and Generalized Distress among Hispanics," Sex Roles 22, no. 7/8 (1990): 441-53.

7. P.J. Farias, "Emotional Distress and Its Socio-Political Correlates in Salvadoran Refugees: Analysis of a Clinical Sample," Culture, Medicine and Psychiatry 15 (1991): 167-92.

8. Beiser; I. Hyman et al., "The Mental Health of Refugee Children in Canada," Refuge 15 (1996): 4-8.

9. Losaria-Barwick; Jenkins; Desjarlais et al.

10. Desjarlais et al.

11. Desjarlais et al.; Salgado de Zinder, Cervantes, and Padilla.

12. J.T. Salvendy, "The Mental Health of Immigrants: A Reassessment of Concepts," Canada's Mental Health 31, no. 1 (1983): 9-16.

13. John T. Berger, "Culture and Ethnicity in Clinical Care," Archives of Internal Medicine, 158 (1998): 2085-90.

14. David Sabo, "Masculinities and Men's Health: Moving toward Post-Superman Era Prevention," in Men's Lives, ed. Michael S. Kimmel and Michael A. Messner (Boston: Allyn and Bacon, 1998.

15. S.H. Frank, "Expectations Disease: A Model for Understanding Stress, Control and Dependent Behavior," Family Practice 10, no. 1 (1993): 23-33.

16. Ibid.

17. D. Umberson, K. Williams, and K. Anderson, "Violent Behaviour: A Measure of Emotional Upset?" Journal of Health and Social Behavior 43 (2002): 189-206.

18. Will H. Courtenay, "Constructions of Masculinity and their Influence on Men's Well-Being: A Theory of Gender and Health," Social Science and Medicine 50 (2000): 1385-401.

19. D. Sabo and D.F. Gordon, Men's Health and Illness: Gender, Power, and the Body (Thousand Oaks, CA: Sage Publications, 1995).

20. R. Brannon, “The Male Sex Role: Our Culture's Blueprint of Manhood, and What It Has Done for Us Lately," in The Forty-Nine Percent Majority, ed. D. David and R. Brannon (Reading, MA: Addison Wesley, 1976).

21. Courtenay.

22. Ibid.

23. Freire.

24. Farias.

25. Freire; and P.J. Guarnaccia and P. Farias, "The Social Meanings of Nervios: A Case Study of a Central American Woman," Social Science and Medicine 26 (1988): 1223-31.

26. Freire.

27. Freire; J.A. Ungemack and P.J. Guarnaccia, "Suicidal Ideation and Suicide Attempts among Mexican Americans, Puerto Rican and Cuban Americans," Transcultural Psychiatry 35, no. 2 (1998): 307-27. 
28. Freire.

29. Ungemack and Guarnaccia.

30. Freire; Meredith.

31. P.J. Guarnaccia, B.J. Good, and A. Kleinman, "A Critical Review of Epidemiological Studies of Puerto Rican Mental Health," American Journal of Psychiatry 147 (1990): 1449-56.

32. Jenkins.

33. Margaret Lock, "Words of Fear, Words of Power: Nerves and the Awakening of Political Consciousness," Medical Anthropology 11 (1989): 79-90; S.M. Low, "Gender, Emotion, and Nervios in Urban Guatemala," in Gender, Health, and Illness: The Case of Nerves, ed. Dona L. Davis and Setha M. Low (New York: Hemisphere Publishing, 1989); Guarnaccia and Farias.

34. S.M. Low, "Embodied Metaphors: Nerves as Lived Experience," in Embodiment and Experience: The Existential Ground of Culture and Self, ed. Thomas J. Csordas (Cambridge: Cambridge University Press, 1994); Charles Taylor, The Ethics of Authenticity (Cambridge, MA: Harvard University Press, 1992).

35. Margaret Lock, "On Being Ethnic: The Politics of Identity Breaking and Making in Canada, or, Nevra on Sunday," Culture, Medicine and Psychiatry 14 (1990): 237-54.

36. Farias; Guarnaccia and P. Farias.

37. Lock, "On Being Ethnic"; David and Low, eds.

38. Low, "Gender, Emotion, and Nervios in Urban Guatemala"; Lock, "On Being Ethnic"; J.D. Koss-Chioino, "Experience of Nervousness and Anxiety Disorders in Puerto Rican Women: Psychiatric and Ethnopsychological Perspectives," in Davis and Low, eds.

39. Farias.

40. Lloyd. H. Rogler, "The Meaning of Culturally Sensitive Research," American Journal of Psychiatry 143, no. 3 (1989): 296-302.

41. A.J. Kuzel, "Sampling in Qualitative Inquiry," in Doing Qualitative Research, $2^{\text {nd }}$ ed., ed. B.F. Crabtree and W.L. Miller (Thousand Oaks, CA: Sage Publications, 1999).

42. R.B. Addison, "A Grounded Hermeneutic Editing Process," in Crabtree and Miller, eds.

43. Aihwa Ong and Michael G. Peletz, eds., "Introduction," in Bewitching Women, Pious Men: Gender and Body Politics in Southeast Asia (Berkeley: University of California Press, 1995).

44. Beiser; B. Behnia, Survivors of War \& Torture: Support Networks and Help-Seeking Experiences (Canadian Mental Health Association, 1999).

45. Freire.

46. Jarama, H. Reyst, M. Rodriguez, et al., "Psychosocial Adjustment among Central American Immigrants with Disabilities: An Exploratory Study," Cultural Diversity \& Mental Health 4, no. 2 (1998): 115-25; M. Beiser, R.J. Turner, and S. Ganesan, "Catastrophic Stress and Factors affecting Its Consequences among Southeast Asian Refugees," Social Science \& Medicine 28, no. 3 (1989): 183-95.

47. Friere.

48. Matthew C. Gutmann, The Meanings of Macho: Being a Man in Mexico City (Berkeley: University of California Press, 1996).

49. Rogler.

50. Freire.
51. Frank.

52. Pierre Bourgois, In Search of Respect: Selling Crack in El Barrio (Cambridge: Cambridge University Press, 1995).

53. Ian Robinson, "Personal Narratives, Social Careers and Medical Courses: Analyzing Life Trajectories in Autobiographies of People with Multiple Sclerosis," Social Science and Medicine 30, no. 11 (1990): 1173-86.

54. J. McIntosh and N. McKeganey, "Addicts' Narratives of Recovery from Drug Use: Constructing a Non-Addict Identity," Social Science and Medicine 50, no. 10 (2000): 1501-10.

55. K. Charmaz, "Loss of Self: A Fundamental Form of Suffering in the Chronically Ill," Sociology of Health and Illness 5 (1983): 168-95.

56. Richard Rechtman, "Stories of Trauma and Idioms of Distress: From Cultural Narratives to Clinical Assessment," Transcultural Psychiatry 37 (2000): 3.

57. Charles Taylor, The Ethics of Authenticity (Cambridge, MA: Harvard University Press, 1992).

58. S.L. Jarama, H. Reyst, M. Rodriguez et al.

59. J.D. Hovey, "Religion and Suicidal Ideation in a Sample of Latin American Immigrants," Psychological Reports 85, no. 1 (1999): 171-77.

Kevin Pottie, M.D., M.Cl.Sc., is Scientist, Institute of Population Health, and Co-Director, Immigrant Health and Visiting Friends and Relatives Program; and Assistant Professor, Department of Family Medicine, University of Ottawa, Ontario, Canada

Judith Belle Brown, Ph.D., is Professor, Thames Valley Family Medicine Research Unit and Centre for Studies in Family Medicine, Department of Family Medicine, University of Western Ontario, London, Ontario, Canada.

Samuel Dunn is Creator/Writer, Banger Productions, Toronto, Ontario, Canada.

The authors extend sincere thanks to the participants and the key informants in this study for sharing their stories and providing critical comments during the analysis of this study. This study was supported by a grant from Citizenship and Immigration Canada. Special thanks are also extended to Dr. Marta Young and Dr. Hamilton Sequeira for their constructive comments in the drafting of this manuscript. 